\title{
Determination of Aflatoxin contaminants in chrysanthemum by HPLC
}

\author{
Zha Yubing ${ }^{1}$, Su Yueping ${ }^{2}$, Yan Yueping g-Chunliang ${ }^{* 1}$, Huang \\ Yingqiang $^{2}$,Wang Xiaofang ${ }^{1}$,
}

\author{
Lin Ling ${ }^{1}$,Zeng Shaodong ${ }^{1}$,
}

(Center for food quality supervision \& testing (Zhangjiang) Ministry of agriculture PRC, Zhanjiang 524001, China; Agricultural technology extension Center, Zhanjiang 524001, China)

Keywords: HPLC; chrysanthemum; Aflatoxins;

Abstract : A method was developed for the simultaneous determination of Afiatoxin ( $\mathrm{AFB}_{1}$ 、 $\mathrm{AFB}_{2} 、 \mathrm{AFG}_{1} 、 \mathrm{AFG}_{2}$ ) in chrysanthemum is developed by Liquid chromatograPhy with fluoreseence detection after immunoaffinity column clean - up and Pre - cloumn derivatization. four south medicine samples were extracted with methanol-water(70:30,v/v), The extracts were Purified by imunoaffinity columns and the toxins were separated by reversed phase HPLC, and quantified with fluorescenee detection after photoehemieal derivatization. The separation was perfored on $\mathrm{C}_{18}$ column. Recoveries of the different medicines spiked with Aflatoxin, The average recoveries ranged from $81.0 \% \sim 94.3 \%$ by addition of avermectin standards at three different concentration levels of $10 \mu \mathrm{g} / \mathrm{kg}$ ) to chrysanthemum as matrixes. The sensitivity, accuracy and precisiothod were able to meet the requirements for pesticide residue analysis.

\section{Introduction}

chrysanthemum, which are rich in Chuzhou,Huangshan,Bozhou,Hangzhou of China. They are called the four most famous chrysanthemum. However, in the process of production, processing, storage, transport, due to the condition and technology simple, It is easy to mildew and produce aflatoxin.Aflatoxins (AFs) are secondary metabolites produced by Wlamentous fungi Aspergillus, particularly Xavus and parasiticus ${ }^{[1]}$.

Aflatoxin contamination during storage is a major problem facing the Agriculture products industry in the world,Especially in the more humid parts. The carcinogenic, mutagenic and immuno-suppressive evects of aflatoxins on several animals have been fully documented ${ }^{[2]}$, and $\mathrm{AFB}_{1}$ has the strongest toxicity In four kinds of aflatoxins.Human liver cancer and levels of aflatoxins in the daily diet are strictly correlated as epidemiological studies show ${ }^{[3]}$.

AFs do not decompose at the temperature of boiling water during the preparation of the drink ${ }^{[4]}$. South Korea KFDA (KFDA) issued the $\mathrm{AFB}_{1}$ standard and test method of Chinese herbal medicine in the notice, requirements, cassia seed, peach kernel, licorice 9 Chinese herbal medicines of $\mathrm{AFB}_{1}$ lower than $10 \mu \mathrm{g} / \mathrm{kg}$. European Commission Regulations set limits for $\mathrm{AFB}_{1}$ and total aflatoxins of $2 \mathrm{ug} / \mathrm{kg}$ and $4 \mathrm{ug} / \mathrm{kg}$ respectively in groundnuts,nuts, dried fruit and cereals since $1998^{[5]}$."China Pharmacopoeia" 2010 edition sets maximum limits also in spices (dried citrus peel. peach kernel and Scaphium scaphigerum (AFB $15 \mathrm{ug} / \mathrm{kg}$,total AFs 10ug/kg). 


\section{Materials and methods}

\section{Instruments, reagents and materials}

Waters 2695 HPLC (Water Corporation); High-speed Homogenizer; Nitrogen blow instrument(United States Organomation); Centrifuge (Japan-Hitachi); Vortex mixer (Germany IKA);Solid-phase extraction device (HP6019); Electronic balance (AUY220, Shimadzu Corporation).

Acetonitrile and dichloromethane was of analytical grade, and methanol was of analytical and HPLC grade. Water was distilled twice. The cartridges used for solid phase extraction was Aflatoxin immunoaffinity column( $3 \mathrm{ml}, 300 \mathrm{ng})$. The concentration of AFs standards was high than $95 \%$. Stock solutions $(1.0 \mathrm{mg} / \mathrm{ml})$ of the reference standards was dissolved in methanol and stored at $-18^{\circ} \mathrm{C}$.

\section{Instrument conditions}

The target was detected by high performance liquid chromatography (HPLC) with a fluorescence detector) $\left(\lambda=360 \mathrm{~nm}\right.$ excitation, $\lambda=435 \mathrm{~nm}$ emission). An Symmetry $\mathrm{C}_{18}(4.6 \times 250 \mathrm{~mm}, 5 \mu \mathrm{m})$ chromatograph column was employed and was operated at $35^{\circ} \mathrm{C}$.Optimum separation was achieved using Gradient elution. Mobile phase consisted of A: acetonitrile; B: water with $0.1 \%(\mathrm{v} / \mathrm{v})$ acetic acid. The gradient was set up as follows: $0 \sim 8.0 \mathrm{~min}, 20 \%-30 \% \mathrm{~A} ; 8.0 \mathrm{~min}, 30 \%$ A,takes ten minutes. The injection volume was $10 \mu \mathrm{L}$, and the flow-rate was $0.3 \mathrm{ml} / \mathrm{min}$.

\section{Preparation for analysis}

Samples $\left(5^{*} 0.01 \mathrm{~g}\right)$ was prepared in $250 \mathrm{~mL}$ cone flask with plug, added $5 \mathrm{~g}$ Sodium chloride and $150 \mathrm{ml} \mathrm{methanol/water(70/30).} \mathrm{After} \mathrm{Homogeneous} \mathrm{for} 2$ minutes, the sample extract was fltered. The immunoaffinity column was washed prior to use with $10 \mathrm{ml}$ phosphatebuffer saline $(\mathrm{pH} 7.4)$ at flow rate of $3 \mathrm{ml} / \mathrm{min}$, then $15 \mathrm{ml}$ of clear filtrate was diluted with $30 \mathrm{ml}$ waters and applied to the conditioned column $(6 \mathrm{ml}$

/min). After that, thecolumn was washed with $10 \mathrm{ml}$ water $(5 \mathrm{ml} / \mathrm{min})$ twice and driedby passing air through it. Finally, bound aflatoxins were eluted slowly with $1.0 \mathrm{ml}$ methanol and pushing air through the column to collect all elution liquid in glass test tube, and finally filtered through 0.22 $\mu \mathrm{m}$ filters. In the end,keep the supematant for analysis.

\section{Accuracy of methods}

Sample with no aflatoxins residue was analyzed following the same procedure as the above samples, at the same time, setting additional levels $10 \mathrm{ug} / \mathrm{kg}$, Recovery and precision of the method were tested by standard addition method. The results of the recovery tests and statistical data are given in Table 1. It indicated that this method has a good accurate.

Table 1 Recovery of aflatoxins B1, B2, G1 and G2 from blanks samples spiked with known concentration of toxin and statistical data

\begin{tabular}{llllll}
\hline & $\mathrm{AFB}_{1}$ & $\mathrm{AFB}_{2}$ & $\mathrm{AFG}_{1}$ & $\mathrm{AFG}_{2}$ \\
\hline & $\begin{array}{l}\text { Recovery (\%) } \\
\text { Standard deviation }\end{array}$ & 81.0 & 88.0 & 91.5 & 94.3 \\
chrysanthemum & 2.3 & 4.6 & 1.9 & 5.2 \\
& $\begin{array}{l}\text { (SD) } \\
\text { Reproducibility (DSR) }\end{array}$ & & & & \\
& 2.7 & 5.2 & 2.1 & 5.8 \\
\hline
\end{tabular}




\section{Results and discussion}

All data were obtained without any interference in the analysis. Aflatoxins analysis on spices are not simple. because of the highly coloured contaminating materials

that are co-extracted with AFs. The $75 \%$ of chrysanthemum resulted contaminated

from four aflatoxins.and $\mathrm{AFB}_{1}$ is high.

\section{Conclusions}

This study provides useful information about the risk of aflatoxins hazard and hopes to raise the consciousness among consumers, researchers, farmers and traders about

the importance to improve processing methods (planting,drying, transporting and storaging) and to establish a monitoring programme on medicine and the necessity to obtain more and more data on the distribution and contamination levels of AFs in south medicines.

\section{Acknowledgments}

This research suproted by the foundation of Quality and Safety Risk Assessment on Agro-products, (Project Number: GJFP2015012).The authors also acknowledge the colleague of Lin Ning,Zeng Shaodong,Li Tao,Su Zipeng,Li Qi, Guo Hongbing Zhang Liqiang and Ye Jianzhi who helped in obtaining the medicinal plants used in this study.

\section{References}

[1]Reddy, S. V., Kiran, Mayi D., Uma, Reddy M., Thirumala-Devi, K., \& Reddy, D. V. R. (2001). Aflatoxins B1 in diVerent grades of chillies (capsicumannum L.) in India as determined by indirect competitive- ELISA.Food Additives and Contaminants, 18, 553-558.

[2] Peraica M, Rad ic B, Lucic A, et. all Toxic effects of mycotoxins in humans[J]. World Health Organ, 1999,77(9):754.

[3]Groopman, J. D., \& Kensler, W. (1996). Temporal patterns of aflatoxin albumin adducts in hepatitis B surface antigen-positive and antigen negative residents of Daxin, Qidong County, People's Republic of China. Cancer Epidemiology Biomarkers and Prevention, 5(4), 253-261.

[4].Feuell, Aj. (1996). Aflatoxin in groundnuts. Part 9: Problems of detoxiWcation.Tropical Science, $8,61-70$.

[5]. Commission Directive 98/53/EC of 16 July 1998 laying down the sampling methods and the methods of analysis for the oYcial control of the levels for certain contaminants in foodstuVs. OYcial Journal of the European Communities, L201/93, Luxembourg. 